\title{
Hetergeneous Sectors, Trade, and Growth
}

\author{
Pengfei Wang, HKUST Danyang Xie, HKUST
}

September 2008

\begin{abstract}
This paper introduces sectorial heterogeneity in TFPs in a growth model driven by an exogenous process of labor specialization to generate new insights on trade and economic growth. Despite the exogeneity of labor specialization, the overall economic growth rate in this model is endogenously determined and depends in a closed economy on the distribution of labor intensity across sectors. Our model could thus be labeled as a semi-endogenous growth model in the sense of Jones (1995). When the model is extended to allow for international trade, we find that the overall growth rate is unambiguously higher as the number of trading partners increases. There are two effects working in the same direction contributing to this result: the resource re-allocation effect and the total product-variety effect. On the other hand, the growth effect of the reduction in trade-related fixed cost is non-monotonic because the two effects work in opposite directions.

$\underline{\text { JEL Classification: }}$
\end{abstract}

Keywords: Heterogeneous Sectors, International Trade, Growth

Acknowledgment: We have benefitted from discussions with Assaf Razin and Yi Wen. The usual disclaimer applies.

Correspondence: Pengfei Wang, Department of Economics, Hong Kong University of Science and Technology, Clear Water Bay, Kowloon, Hong Kong; E-mail: pfwang@ust.hk 


\section{Introduction}

It comes as no surprise that productivity growth is dramatically different across sectors. Table 1, extracted from Jorgenson and Gollop (1992), highlights this difference in the case of the U.S.A. for the post-war period between 1947-85. Using OECD's intersectoral database, Bernard and Jones (1996) document TFP differences both across sectors and across countries (see their Table 1). As a first step, we ignore TFP differences across countries in this paper. Rather, we focus on TFP differences across sectors and investigate how these differences affect the aggregate growth. Furthermore, we examine the interaction between international trade and growth. Clearly, we need to go beyond "one sector" growth models (Solow 1956, for example) to incorporate differences in sector-level productivity growth.

Table 1. Average Annual TFP Growth Across Sectors (in \%)

\begin{tabular}{|l|l|}
\hline Agriculture & 1.58 \\
\hline Manufacturing & 0.72 \\
\hline Transportation & 0.96 \\
\hline Communications & 2.04 \\
\hline Utilities & 0.87 \\
\hline Trade & 0.90 \\
\hline Fire & 0.24 \\
\hline Other Services & -0.13 \\
\hline
\end{tabular}

To gain more insight into the impact of heterogeneity, we develop a model that is highly tractable. This is achieved by two technical assumptions. First, we adopt a special case of the production function used in Acemoglu, Antras and Helpman (2007), which greatly simplifies the aggregation. Second, we assume that growth is driven by an exogenous process of labor specialization. This, together with the assumption of heterogeneous labor intensity across sectors, will generate a spectrum of sectorial TFPs. We show that, in this case, the growth rate of the aggregate output is a weighted average of the sectorial productivity growth rates. In a closed economy model, the particular way that we model heterogeneity in sectorial productivity growth implies that the weights depend on the distribution of labor intensity across sectors. When the model is extended to an open economy, the weights also depend on trade parameters. Hence, our model could be labeled as a semi-endogenous growth model in the sense of Jones (1995) to distinguish it from the endogenous growth models of Romer (1986, 1990), Lucas (1988), Grossman and Helpman (1991) and Aghion and Howitt (1992). 
The main findings of this paper are as follows. First, we identify a resource reallocation effect: only the relatively more productive sectors engage in international trade and the resources are directed more toward these sectors than in the closed economy case. We show that this is an equilibrium outcome and is consistent with the assumption underlying Harrod-Balassa-Samuelson hypothesis that the average technology progress in tradable sectors is faster than in nontradables ones. Our result, obtained by a fully dynamic growth model, complements the insights obtained from stationary models of Eaton and Kortum Samuel (2002), Bernard, Eaton, Jensen and Kortum (2003), Melitz (2003), Helpman, Melitz and Yeaple (2004), Ghironi and Melitz (2005), Bernard, Redding and Schott (2007) and Melitz and Ottaviano (2008). The common theme of this New Trade Theory is that trade liberalization leads to reallocations of resources among firms: the least productive firms are forced to exit and the more productive firms enter the export sector and benefit from a larger international market. The New Trade Theory has been cross-confirmed in a number of empirical studies. ${ }^{1}$ For example, Bernard and Jensen (1995, 1999), Aw, Chung, and Roberts (2000), Eaton, Kortum, and Kramarz (2004), among others, have documented that differences in firm productivity are strongly correlated with a firm's decision to engage in international transactions (such as exporting, importing intermediate goods from foreign suppliers, or investing in foreign subsidiaries).

Second, our approach has the advantage that resource-reallocation produces a growth effect rather than a one-time level effect. We show that the growth rate is unambiguously higher as the number of trading partners increases. There are two effects working in the same direction contributing to this result: the resource reallocation effect and the total product-variety effect. More trading partners intensify the competition and resources are reallocated to the sectors with higher productivity growth, inducing higher overall growth. The total product-variety effect is less straightforward than we might otherwise think. As the number of trading partners increases, each country exports a narrower set of goods, but the total variety of exports expands, leading to higher overall growth. This fits well with empirical evidence on the positive relationship between growth and various measures of openness. In particular, Sala-i-Martin (1997) shows that, in a cross country study, the number of years an economy has been open is robustly linked to high growth; Frankel and Romer (1999), using countries' geographic characteristics as instrumental variables, find

\footnotetext{
${ }^{1}$ See Melitz (2007) for a survey on the New Trade Theory.
} 
evidence suggesting that trade has a quantitatively large and robust positive effect on income; Alcala and Ciccone (2004) introduced a concept of "real openness" to show its significant and statistically robust positive effect on productivity. ${ }^{2}$ The charts in Lucas (2007) also suggest that openness (classified based on the five-test approach in Sachs and Werner, 1995) is positively linked to growth.

Our third result is that the growth effect of a reduction in trade-related fixed cost is non-monotonic. When the trade-related fixed cost increases, the resource reallocation effect and the total product-variety effect work in opposite directions. Whereas the resource reallocation effect continues to induce higher growth because the average growth rates of the exporters are pushed higher by the higher fixed cost, the total product-variety available to each country shrinks.

The remainder of this paper is organized as follows. In Section 2, we set up a closed economy model incorporating heterogeneous productivity growth across sectors. We show that the overall growth rate is a weighted average of the productivity growth across sectors. In Section 3, we extend the model to an open economy and characterize the endogenous trade patterns at the equilibrium and the labor market allocation. In Section 4, we examine the interaction between trade and growth. Section 5 concludes the paper and suggests directions for future research.

\section{A Closed Economy Model}

We focus on modelling the heterogeneity of productivity growth across sectors. For tractability, we abstract away from capital and make no attempt to model investment and savings decisions.

\subsection{Final Good Production}

The production of the closed economy consists of two layers. The top layer produces a final good in a competitive market by combining a continuum of sectoral goods from the lower layer.

\footnotetext{
${ }^{2}$ Alcala and Ciccone (2004) define "real openness" as imports plus exports in exchange-rate U.S. dollars relative to GDP in purchasing power parity U.S. dollars in an attempt to eliminate distortions due to crosscountry differences in the relative price of non-tradable goods.
} 
The production function for the final good takes the following Cobb-Douglas form:

$$
Y=\Omega^{\kappa+1} \exp \left(\frac{1}{\Omega} \int_{i \in \Omega} \log (Y(i)) d i\right),
$$

where $\Omega$ is the measure of different types of sectoral goods available and $\kappa>0$ captures the extent of increasing returns to specialization. This production function is the limiting case of the CES-type used by Acemoglu, Antras and Helpman (2007,) when their elasticity of substitution approaches unity. As noted in their paper, this functional form exhibits: (1) constant returns to scale; (2) constant elasticity of substitution; and (3) constant elasticity of output with respect to $\Omega$.

Finally, this production function implies equal cost-shares for different sectoral inputs, and hence guarantees balanced growth in all sectors. Normalizing the price of final good to unity, the first order condition for the profit maximization on the part of the final goods producers yields the following inverse demand curve for sector $i$ :

$$
P_{t}(i) Y_{t}(i)=\frac{1}{\Omega} Y_{t} .
$$

\subsection{Sectorial Goods Production}

In each of the sectors, for example, sector $i$, there is a continuum of firms with measure 1 , producing differentiated intermediate goods that are aggregated into a sectoral good by a CES aggregator:

$$
Y_{t}(i)=\left[\int_{0}^{1} y_{t}^{\frac{\sigma-1}{\sigma}}(j, i) d j\right]^{\frac{\sigma}{\sigma-1}},
$$

where $y_{t}(j, i)$ is the output of the $j^{\text {th }}$ firm in the $i^{\text {th }}$ sector. The elasticity of substitution between any two intermediate goods in a sector is constant and equals $\sigma>1$.

In sector $i$, firms are identical. Let $n_{t}(a, j, i)$ be the labor used in process $a$ in firm $j$ in the $i^{\text {th }}$ sector. We use $n_{t}(j, i)$ to denote the total employment in firm $j$, sector $i$. The production function of this firm is defined as follows:

$$
y_{t}(j, i)=\max \int_{0}^{A_{t}}\left[n_{t}(a, j, i)\right]^{1-\theta_{i}} d a
$$

subject to

$$
\int_{0}^{A_{t}} n_{t}(a, j, i) d a \leq n_{t}(j, i)
$$


where $A_{t}$ is a general index of labor specialization in period $t$ and is common for all sectors, and $\theta_{i}$ is a parameter that measures to what extent the division of labor can improve the production efficiency in the $i^{\text {th }}$ sector. ${ }^{3}$ It is easy to see that the resulting production function has a Cobb-Douglas representation:

$$
y_{t}(j, i)=A_{t}^{\theta_{i}} n_{t}^{1-\theta_{i}}(j, i) .
$$

A sector with lower $\theta_{i}$ (a more labor-intensive sector) benefits less from an expanding division of labor, $A$. In the extreme case of $\theta_{i}=0$, labor specialization does not affect output at all.

The Intermediate Good Producer's Problem: In the $i^{\text {th }}$ sector, the conditional demand faced by intermediate goods producing firm $j, y_{t}(j, i)$, at price $p_{t}(j, i)$ is:

$$
y_{t}(j, i)=\left(\frac{P_{t}(i)}{p_{t}(j, i)}\right)^{-\sigma} Y_{t}(i),
$$

where $P_{t}(i)$ is the $i^{t h}$ sectoral good's price and $Y_{t}(i)$ is the $i^{\text {th }}$ sectoral good's output. The sectoral price, $P_{t}(i)$, in period $t$ is:

$$
P_{t}(i)=\left[\int_{0}^{1} p_{t}^{1-\sigma}(j, i) d j\right]^{\frac{1}{1-\sigma}} .
$$

The total profit for firm $j$ in sector $i$ is its revenue minus wage cost, $\pi_{t}(j, i)=p_{t}(j, i) y_{t}(j, i)-$ $w_{t} n_{t}(j, i)$. The firm $j$ solves its profit maximization problem given its demand function (4) and its production function (3). A solution to the monopolistic firm's problem yields the following first-order condition:

$$
\frac{1-\sigma}{\sigma}\left(1-\theta_{i}\right) p_{t}(j, i) y_{t}(j, i)=w_{t} n_{t}(j, i)
$$

\subsection{The Equilibrium}

Given the symmetry built into the production function (2), we obtain that, at equilibrium,

$$
\begin{aligned}
& y_{t}(j, i) \equiv Y_{t}(i), \\
& p_{t}(j, i) \equiv P_{t}(i),
\end{aligned}
$$

\footnotetext{
${ }^{3}$ The assumption that $A_{t}$ is common to all sectors is innocuous. As long as the distributions of the growth rate of $A_{t}(i)$ and of $\theta_{i}$ are independent, we can show that all the results in the closed-economy and the open economy remain valid.
} 
and

$$
n_{t}(j, i) \equiv N_{t}(i)
$$

for any $j$.

Equation (6) then becomes :

$$
\frac{1-\sigma}{\sigma}\left(1-\theta_{i}\right) P_{t}(i) Y_{t}(i)=w_{t} N_{t}(i)
$$

Hence, for any two sectors, $i$ and $l$, the above equation together with $P_{t}(i) Y_{t}(i)=P_{t}(l) Y_{t}(l)=$ $\frac{1}{\Omega} Y_{t}$ (see equation (1)) implies:

$$
\frac{N_{t}(l)}{N_{t}(i)}=\frac{1-\theta_{l}}{1-\theta_{i}}
$$

The condition for labor market equilibrium requires that the total labor demand across sectors equal the total labor supply, $N_{t}$, which we assume to be equal to a constant, $N$ :

$$
\int_{0}^{\Omega} N_{t}(l) d l=N .
$$

After replacing $N_{t}(l)$ with $N_{t}(i)$ by making use of equation (7) and letting $\bar{\theta}$ be the average of $\theta_{l}$ across sectors, the labor allocated to the $i^{\text {th }}$ sector is :

$$
N_{t}(i)=\frac{\left(1-\theta_{i}\right) N}{(1-\bar{\theta}) \Omega} \text {. }
$$

This model implies that the sector with less productivity growth (lower $\theta_{i}$ ) would employ more labor in equilibrium. And the implied sectorial output in sector $i$ is

$$
Y_{t}(i)=A_{t}^{\theta_{i}}\left[\frac{\left(1-\theta_{i}\right) N}{(1-\bar{\theta}) \Omega}\right]^{1-\theta_{i}} .
$$

Finally, the output of the final good in period $t$ is

$$
\begin{aligned}
Y_{t} & =\Omega^{\kappa+1} \exp \left[\frac{1}{\Omega} \int_{i \in \Omega}\left[\theta_{i} \log A_{t}+\left(1-\theta_{i}\right)\left[\log N+\log \left(1-\theta_{i}\right)-\log (1-\bar{\theta})-\log \Omega\right]\right] d i\right] \\
& =\Omega^{\kappa+\bar{\theta}} N^{1-\bar{\theta}} A_{t}^{\bar{\theta}} \Phi
\end{aligned}
$$

where $\Phi$ is a constant and equal to $\frac{1}{(1-\bar{\theta})^{1-\theta}} \exp \frac{1}{\Omega} \int_{i \in \Omega}\left(1-\theta_{i}\right) \log \left(1-\theta_{i}\right) d i$. Let the labor specialization process follow an exogenous growth pattern: $\frac{\dot{A}_{t}}{A_{t}}=g$. The growth rate of the aggregate output is hence $\bar{\theta} g$, which is the average output growth rate across sectors (see equations 11 and 10). The output we obtain here also highlights an important advantage of our setup: despite the fact that different sectors grow at different rates, the overall economy has a constant growth rate. It also indicates that the economic growth rate would be endogenous if $\bar{\theta}$ could be affected by policies. As we shall show as an example in the next section, $\bar{\theta}$ can depend on the trade policy in an open economy model. 


\section{An Open Economy Model}

We begin with a symmetric two-country model and then generalize our equilibrium characterization to a symmetric $m+1$-country case.

We denote the two countries as home, $H$, and foreign, $F$. The final good production function at home is given by:

$$
Y_{H}=\Omega_{H}^{\kappa+1} \exp \left\{\frac{1}{\Omega_{H}}\left[\int_{i \in \Gamma_{H}} \log Y_{H}^{H}(i) d i+\int_{i \in I_{H}} \log Y_{H}^{F}(i) d i\right]\right\},
$$

where $Y_{H}^{H}(i)$ denotes the sectorial goods, $i \in \Gamma_{H}$, that are produced using domestic intermediate goods and $Y_{H}^{F}(i)$ denotes the sectorial goods, $i \in I_{H}$, that are produced using imported intermediate goods; $\Omega_{H}$ is the total measure of the set $\Gamma_{H}$ (which we assume to be unity) plus $I_{H}$ (which, with abuse of notation, also denotes the measure of set $I_{H}$ ), namely, $\Omega_{H}=1+I_{H}$. In our notation, whenever both the subscript and superscript appear at the same time, the subscript indicates the location of the sectorial output and the superscript indicates the origin of intermediate inputs.

Similarly, the final good production function in the foreign country is given by

$$
Y_{F}=\Omega_{F}^{\kappa+1} \exp \left\{\frac{1}{\Omega_{F}}\left[\int_{i \in \Gamma_{F}} \log Y_{F}^{F}(i) d i+\int_{i \in I_{F}} \log Y_{F}^{H}(i) d i\right]\right\} .
$$

As in the trade literature, we assume that an intermediate good producer must incur a fixed cost, $\phi$ (in units of labor), to engage in international trade. An iceberg cost, which

is typically assumed in trade models, is not essential here and is assumed out from the beginning. To facilitate the analysis, we also impose symmetry across countries. The real exchange rate between final goods is therefore unity. Given prices $\left\{P_{H}^{H}(i), i \in \Gamma_{H}\right\}$ and $\left\{P_{H}^{F}(i), i \in I_{H}\right\}$, profit maximization by the final goods producer implies that the demand in the home country for each sectorial good $i$ is:

$$
\begin{aligned}
& Y_{H}^{H}(i)=\frac{1}{\Omega_{H}} \frac{Y_{H}}{P_{H}^{H}(i)}, i \in \Gamma_{H} \\
& Y_{H}^{F}(i)=\frac{1}{\Omega_{H}} \frac{Y_{H}}{P_{H}^{F}(i)}, i \in I_{H},
\end{aligned}
$$

and similarly the demand in the foreign country for each sectorial good $i$ is:

$$
\begin{gathered}
Y_{F}^{F}(i)=\frac{1}{\Omega_{F}} \frac{Y_{F}}{P_{F}^{F}(i)}, i \in \Gamma_{F} \\
Y_{F}^{H}(i)=\frac{1}{\Omega_{F}} \frac{Y_{F}}{P_{F}^{H}(i)}, i \in I_{F} .
\end{gathered}
$$


Similar to its counterpart in the closed economy, each of the goods in sector $i \in \Gamma_{H}$ is produced by a continuum of domestic intermediate goods according to a CES aggregating function:

$$
Y_{H}^{H}(i)=\left[\int_{0}^{1}\left(y_{H}^{H}(j, i)\right)^{\frac{\sigma-1}{\sigma}} d j\right]^{\frac{\sigma}{\sigma-1}}, \sigma>1,
$$

and each of the goods in sector $i \in I_{H}$ is produced from a continuum of imported intermediate goods:

$$
Y_{H}^{F}(i)=\left[\int_{0}^{1}\left(y_{H}^{F}(j, i)\right)^{\frac{\sigma-1}{\sigma}} d j\right]^{\frac{\sigma}{\sigma-1}} .
$$

Analogously, for each $i \in I_{F}$, the sectorial goods are an aggregator of a continuum of intermediate goods produced in the home country:

$$
Y_{F}^{H}(i)=\left[\int_{0}^{1}\left(y_{F}^{H}(j, i)\right)^{\frac{\sigma-1}{\sigma}} d j\right]^{\frac{\sigma}{\sigma-1}} .
$$

And, for each of $i \in \Gamma_{F}$,

$$
Y_{F}^{F}(i)=\left[\int_{0}^{1}\left(y_{F}^{F}(j, i)\right)^{\frac{\sigma-1}{\sigma}} d j\right]^{\frac{\sigma}{\sigma-1}}
$$

\subsection{Intermediate-good Producers}

The Intermediate Good Producer's Problem for Sector $i \in I_{F}$. We first study the profit maximization problem of intermediate goods producers in sectors that serve both the home and foreign countries. The domestic demand for an intermediate goods produced by a firm $j \in[0,1]$ in the $i^{\text {th }}$ sector such that $i \in I_{F}$ (namely, firm $j$ is located in country $H$ ) is given by,

$$
y_{H}^{H}(j, i)=\left[\frac{p_{H}^{H}(j, i)}{P_{H}^{H}(i)}\right]^{-\sigma} Y_{H}^{H}(i),
$$

and its foreign demand is given by,

$$
y_{F}^{H}(j, i)=\left[\frac{p_{F}^{H}(j, i)}{P_{F}^{H}(i)}\right]^{-\sigma} Y_{F}^{H}(i),
$$

where $p_{H}^{H}(j, i)$ is its price in the home country and $p_{F}^{H}(j, i)$ is its price in the foreign country; $P_{H}^{H}(i)$ and $P_{F}^{H}(i)$ are the sectorial price aggregators in the home country and foreign country, respectively. Let the labor employment in firm $j$ in sector $i$ for purpose of production be $n_{H}(j, i)$. Firm $j$ 's total profit is

$$
\pi_{H}(j, i)=y_{H}^{H}(j, i) p_{H}^{H}(j, i)+p_{F}^{H}(j, i) y_{F}^{H}(j, i)-w n_{H}(j, i)
$$


The firm's problem is to maximize its profit subject to its demand function specified in equations (21) and (22), and its production function:

$$
y_{H}^{H}(j, i)+y_{F}^{H}(j, i)=A^{\theta_{i}}\left(n_{H}(j, i)\right)^{1-\theta_{i}} .
$$

Note that we make use of the same production function rationalized above in the closed economy model.

The monopolistic firm's problem yields the following first-order conditions:

$$
p_{H}^{H}(j, i) y_{H}^{H}(j, i) \frac{\sigma-1}{\sigma}=w \frac{\frac{1}{1-\theta_{i}}}{A^{\frac{\theta_{i}}{1-\theta_{i}}}}\left[y_{H}^{H}(j, i)+y_{F}^{H}(j, i)\right]^{\frac{1}{1-\theta_{i}}-1} y_{H}^{H}(j, i),
$$

and

$$
p_{F}^{H}(j, i) y_{F}^{H}(j, i) \frac{\sigma-1}{\sigma}=w \frac{\frac{1}{1-\theta_{i}}}{A^{\frac{\theta_{i}}{1-\theta_{i}}}}\left[y_{H}^{H}(j, i)+y_{F}^{H}(j, i)\right]^{\frac{1}{1-\theta_{i}}-1} y_{F}^{H}(j, i) .
$$

These two equations then imply:

$$
w n_{H}(j, i)=\frac{\sigma-1}{\sigma}\left(1-\theta_{i}\right)\left[y_{H}^{H}(j, i) p_{H}^{H}(j, i)+p_{F}^{H}(j, i) y_{F}^{H}(j, i)\right] \text { for } i \in I_{F},
$$

which can be substituted into the profit function to arrive at:

$$
\pi_{H}(j, i)=\left[1-\frac{\sigma-1}{\sigma}\left(1-\theta_{i}\right)\right]\left[y_{H}^{H}(j, i) p_{H}^{H}(j, i)+p_{F}^{H}(j, i) y_{F}^{H}(i)\right] \text { for } i \in I_{F} .
$$

Its net profit after paying the fixed cost is $\pi_{H}(j, i)-\phi w$.

The Intermediate Good Producer's Problem for Sector $i \in \Gamma_{H} \backslash I_{F}$. These are the sectors that do not engage in international trade. Hence the firm's problem is the same as we study in the closed economy. The solution to the profit maximization yields

$$
w n_{H}(j, i)=\frac{\sigma-1}{\sigma}\left(1-\theta_{i}\right) y_{H}^{H}(j, i) p_{H}^{H}(j, i) \text { for } i \in \Gamma_{H} \backslash I_{F},
$$

and

$$
\pi_{H}(j, i)=\left[1-\frac{\sigma-1}{\sigma}\left(1-\theta_{i}\right)\right] y_{H}^{H}(j, i) p_{H}^{H}(j, i) \text { for } i \in \Gamma_{H} \backslash I_{F} .
$$

\subsection{The Equilibrium}

We assume that the total labor supply, $N_{H}=N_{F}=N$, in the two countries is the same and is constant over time, and the parameters $\theta_{i}$ for $i \in \Gamma_{H}$ and $i \in \Gamma_{F}$ are independently drawn from a common density function, $f(\theta)$, with support $[0,1]$. By symmetry across countries, we have $Y_{H}=Y_{F}=Y$ and $\Omega_{H}=\Omega_{F}=\Omega$ and $I_{F}=I_{H}=I$ in equilibrium. Note that the equality here is in terms of the measures and not in terms of the sets themselves. 
As in the closed economy, symmetry of firms in a sector implies that for the intermediate goods producers engaging in international trade, we have:

$$
y_{H}^{H}(j, i)=Y_{H}^{H}(i) ; p_{H}^{H}(j, i)=P_{H}^{H}(i) ; p_{F}^{H}(j, i)=P_{F}^{H}(i) ; y_{F}^{H}(j, i)=Y_{F}^{H}(i) \text { for } i \in I_{F},
$$

and for those that do not export, we have:

$$
y_{H}^{H}(j, i)=Y_{H}^{H}(i) ; p_{H}^{H}(j, i)=P_{H}^{H}(i) ; \text { for } i \in \Gamma_{H} \backslash I_{F} \text {. }
$$

Applying equations $P_{H}^{H}(i) Y_{H}^{H}(i)=\frac{1}{\Omega_{H}} Y_{H}, i \in \Gamma_{H}$ and $P_{F}^{H}(i) Y_{F}^{H}(i)=\frac{1}{\Omega_{F}} Y_{F}, i \in I_{F}$ (see equations 14 and 16) and suppressing the reference to $j$ given the symmetry in sectors, we can write the net profit as follows:

$$
\pi(i)=\left\{\begin{array}{cc}
{\left[1-\frac{\sigma-1}{\sigma}\left(1-\theta_{i}\right)\right] \frac{2 Y}{\Omega}-\phi w} & \text { if } i \in I \\
{\left[1-\frac{\sigma-1}{\sigma}\left(1-\theta_{i}\right)\right] \frac{Y}{\Omega}} & \text { if } i \in \Gamma \backslash I
\end{array}\right.
$$

where $\left[1-\frac{\sigma-1}{\sigma}\left(1-\theta_{i}\right)\right] \frac{Y}{\Omega} \geq \phi w$ must hold for $i \in I$ in order for the intermediate goods producers in these sectors to make a non-negative profit from exporting. Note that $\pi(i)$ is increasing in $\theta_{i}$ for $i \in I$ and $i \in \Gamma \backslash I$. Hence, there exists a threshold $\theta^{*}$ such that the intermediate goods producers will choose to export only if they belong to a sector, $i$, with $\theta_{i} \geq \theta^{*}$. This is further clarified in the following proposition with the proof given in an Appendix.

Proposition 1. Let $\phi_{\min }$ and $\phi_{\max }$ be given as:

$$
\phi_{\min }=\frac{N}{1+2(\sigma-1)(1-\bar{\theta})} \text { and } \phi_{\max }=\frac{\sigma N}{(\sigma-1)(1-\bar{\theta})} .
$$

The set, $I$, of sectors that use imported intermediate inputs can be characterized as:

$$
I=\left\{\begin{array}{llr}
\emptyset & \text { iff } & \phi>\phi_{\max } \\
\Gamma & \text { iff } & \phi \leq \phi_{\min } \\
\left\{i \mid 1 \geq \theta_{i} \geq \theta^{*}>0\right\} & \text { iff } & \phi \in\left(\phi_{\min }, \phi_{\max }\right]
\end{array}\right.
$$

where $\theta^{*}$ is the solution to the following labor market equilibrium condition and the zero net-profit condition from exporting:

$$
\begin{gathered}
n^{*}\left[\frac{1-\bar{\theta}}{1-\theta^{*}}+\frac{1}{1-\theta^{*}} \int_{\theta^{*}}^{1}(1-\theta) f(\theta) d \theta\right]+\phi\left[1-F\left(\theta^{*}\right)\right]=N, \\
{\left[\frac{1}{\frac{\sigma-1}{\sigma}\left(1-\theta^{*}\right)}-1\right] n^{*}=\phi,}
\end{gathered}
$$

where $n^{*}$ is the labor input of sector $\theta^{*}$ for the domestic market as established below. ${ }^{4}$

\footnotetext{
${ }^{4}$ We need $(\sigma-1)(1-\bar{\theta})(1-2 \sigma)<\sigma$ to ensure that $\phi_{\min }<\phi_{\max }$. For $\bar{\theta} \in[0,1]$, this holds for all $\sigma>1$.
} 


\subsection{M+1-Country Model}

We now extend our two-country model into $m+1$ symmetric countries. It is straightforward to extend Proposition 1 to the case of $m+1$ symmetric countries as follows (proof available on request).

Proposition 2. Let $\phi_{\min }$ and $\phi_{\max }$ be given as:

$$
\phi_{\min }=\frac{N}{(\sigma-1)(1-\bar{\theta})(m+1)+m} \text { and } \phi_{\max }=\frac{\sigma N}{(\sigma-1)(1-\bar{\theta})} .
$$

The set, $I$, of sectors that use imported intermediate inputs can be characterized as:

$$
I=\left\{\begin{array}{llr}
\emptyset & \text { iff } & \phi>\phi_{\max } \\
\Gamma & \text { iff } & \phi \leq \phi_{\min } \\
\left\{i \mid 1 \geq \theta_{i} \geq \theta^{*}(\phi)>0\right\} & \text { iff } & \phi \in\left(\phi_{\min }, \phi_{\max }\right.
\end{array}\right]
$$

where $\theta^{*}$ is the solution to the following labor market equilibrium condition and the zero net-profit condition from exporting:

$$
\begin{gathered}
n^{*}\left[\frac{1-\bar{\theta}}{1-\theta^{*}}+\frac{m}{1-\theta^{*}} \int_{\theta^{*}}^{1}(1-\theta) f(\theta) d \theta\right]+\phi m\left[1-F\left(\theta^{*}\right)\right]=N, \\
{\left[\frac{1}{\frac{\sigma-1}{\sigma}\left(1-\theta^{*}\right)}-1\right] n^{*}=\phi,}
\end{gathered}
$$

where $n^{*}$ is the labor input of sector $\theta^{*}$ for the domestic market.

Remark. Define $n$ as $\frac{1-\bar{\theta}}{1-\theta^{*}} n^{*}$, which is the total domestic labor input used for domestic market $^{5}$. It is more convenient to rewrite the equilibrium conditions in term of $n$ and $\theta^{*}$ :

$$
\begin{gathered}
n\left[1+\frac{m}{1-\bar{\theta}} \int_{\theta^{*}}^{1}(1-\theta) f(\theta) d \theta\right]+\phi m\left[1-F\left(\theta^{*}\right)\right]=N, \\
{\left[\frac{1-\frac{\sigma-1}{\sigma}\left(1-\theta^{*}\right)}{\frac{\sigma-1}{\sigma}(1-\bar{\theta})}\right] n=\phi .}
\end{gathered}
$$

The labor market equilibrium condition (LME) and the zero net profit condition (ZNP) from exporting represent two different linkages between $n$ and the cut-off $\theta^{*}$. In the diagrams

\footnotetext{
${ }^{5}$ In the case with $m+1$ symmetric countries, the employment in sector $\theta$ is given by,

$$
N(\theta)=\left\{\begin{array}{cc}
\frac{1-\theta}{1-\theta^{*}}(m+1) n^{*}+m \phi & \text { for } \theta \geq \theta^{*} \\
\frac{1-\theta}{1-\theta^{*}} n^{*} & \text { for } \theta<\theta^{*}
\end{array},\right.
$$

The portion of labor used for the domestic market for any $\theta \in[0,1]$ is always $\frac{1-\theta}{1-\theta^{*}} n^{*}$. Thus, the total sums to $\frac{1-\bar{\theta}}{1-\theta^{*}} n^{*}$.
} 
below, we fix $\phi \in\left(\phi_{\min }, \phi_{\max }\right)$. In the $\left(\theta^{*}, n\right)$-space, the LME curve is upward sloping. As $\theta^{*}$ increases, fewer sectors engage in trade and more labor can be used for domestic purposes. The ZNP curve is downward sloping. According to equation (29), wn is proportional to the income level, $Y$. Thus, the market size increases as $n$ increases. Given that the income of the trading partners also increases due to symmetry, more sectors would make positive profits from exporting. That is, as $n$ increases, $\theta^{*}$ decreases. The shapes of the LME and ZNP curves guarantee the uniqueness of the equilibrium.

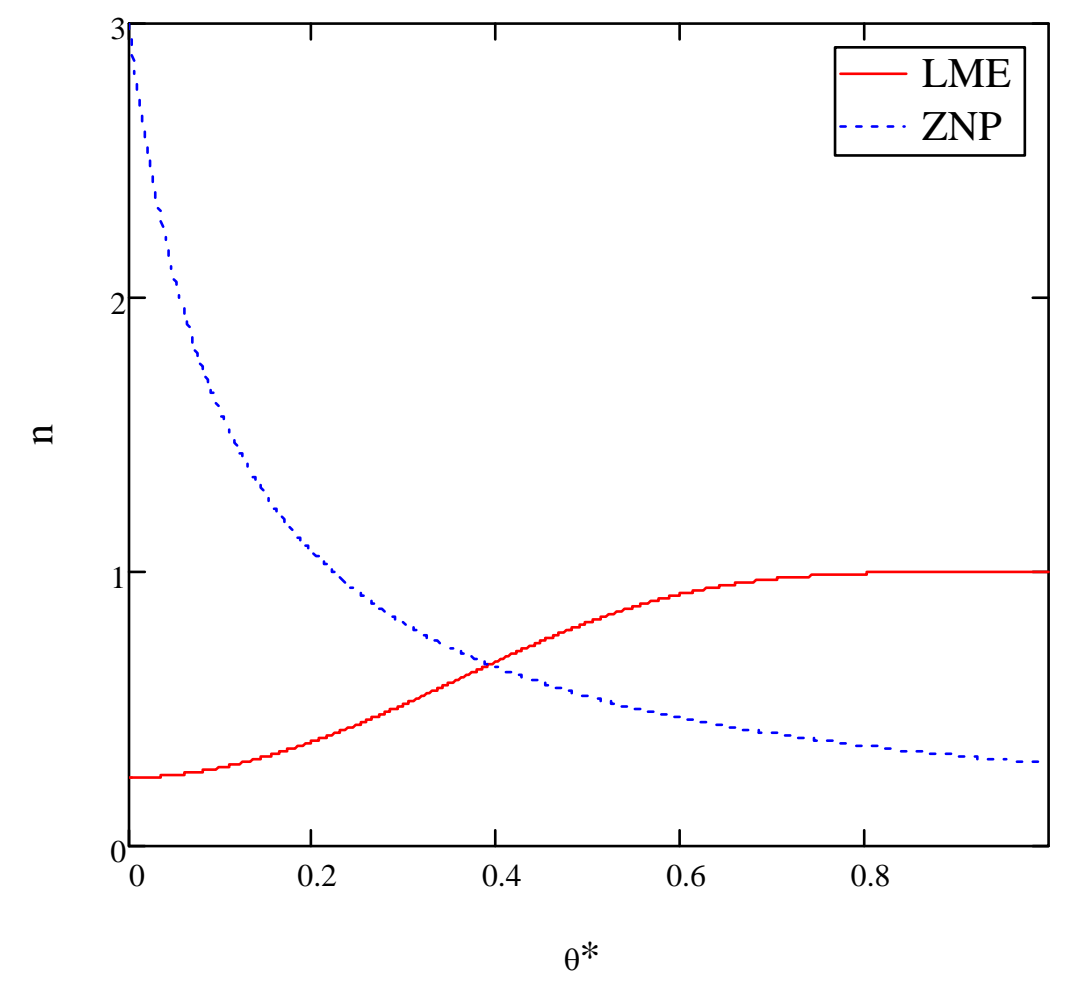

Figure 1. The LME and ZNP Curves when $\phi \in\left(\phi_{\min }, \phi_{\max }\right)$

In general, as $\phi \in\left(\phi_{\min }, \phi_{\max }\right)$ decreases, $\theta^{*}$ decreases whereas $n$ is ambiguous. To see this, note that the ZNP curve shifts to the left because, for any given market size $n$, the lower fixed cost means that more sectors will find it profitable to engage in trade ( $\theta^{*}$ smaller). The LME curve moves up since, for any given $\theta^{*}$, as the fixed cost decreases, the equilibrium in the labor market then implies that there would be more labor for domestic purposes.

In Figure 2, the left panel shows the case when the fixed cost is above $\phi_{\max }$. In this case, even the most productive sector will not profitably engage in trade. The right panel shows 
the case when the fixed cost is below $\phi_{\min }$. In this case, all sectors engage profitably in trade.
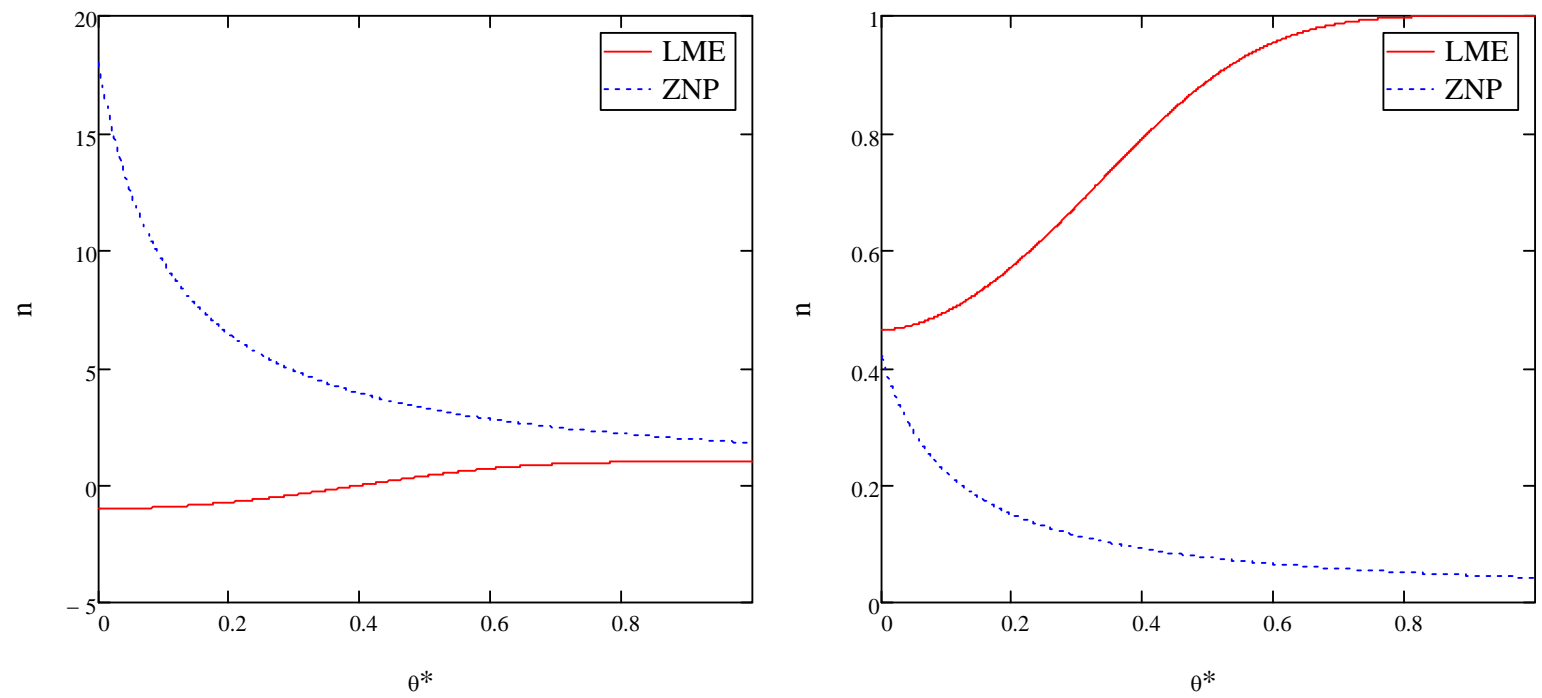

Figure 2. Left Panel (no trade) and Right Panel (full trade)

Final Output Production: In order to calculate the final output in each country, we first calculate the sectorial goods in each sector $\theta$. For a sector with $\theta<\theta^{*}$, we have $N(\theta)=\frac{1-\theta}{1-\theta^{*}} n^{*}=\frac{1-\theta}{1-\theta} n$ and the production in this sector is $Y(\theta)=A^{\theta}\left[\frac{1-\theta}{1-\theta} n\right]^{1-\theta}$. For a sector with $\theta \geq \theta^{*}$, we have $N(\theta)=\frac{(1-\theta)(m+1)}{1-\theta^{*}} n^{*}+m \phi=\frac{(1-\theta)(m+1)}{1-\theta} n+m \phi$, and the total production in this sector is $Y(\theta)=A^{\theta}\left[\frac{(1-\theta)(m+1)}{1-\bar{\theta}} n\right]^{1-\theta}$. Since goods in these traded sectors are used by all $(m+1)$ countries, each country uses $Y(\theta) /(m+1)=A^{\theta}(m+1)^{-\theta}\left[\frac{(1-\theta)}{1-\theta} n\right]^{1-\theta}$. In each of these countries, the total available variety of sectorial goods is $\Omega=1+m\left[1-F\left(\theta^{*}\right)\right]$. Define $\frac{(1-\theta)}{1-\bar{\theta}}=a(\theta)$. The total production of final output in each country is

$$
Y=\Omega^{1+\kappa} \exp \left\{\frac{1}{\Omega}\left[\begin{array}{l}
\int_{0}^{\theta *} \log \left(A^{\theta}[a(\theta) n]^{1-\theta}\right) f(\theta) d \theta \\
+(m+1) \int_{\theta *}^{1} \log \left(\left(\frac{A}{m+1}\right)^{\theta}[a(\theta) n]^{1-\theta}\right) f(\theta) d \theta
\end{array}\right]\right\} .
$$

It follows that the output growth rate is

$$
\frac{\dot{Y}}{Y}=\frac{1}{\Omega}\left[\int_{0}^{\theta^{*}} \theta f(\theta) d \theta+(m+1) \int_{\theta^{*}}^{1} \theta f(\theta) d \theta\right] \frac{\dot{A}}{A} .
$$

Notice that the economic growth rate depends not only on $g_{A}$, but also on the endogenously determined cut-off, $\theta^{*}$. Hence, the economic growth rate is also endogenous in the open economy. 
Hence this model provides an alternative way to model economic growth beyond the current endogenous growth literature pioneered by Romer (1986) and Lucas (1988). In their frameworks, trade can stimulate economic growth by encouraging more resources for $\mathrm{R} \& \mathrm{D}$ and hence speed up technology progress. In our model, trade affects growth through a resource reallocation channel. Trade exposure allows a country to improve efficiency by reducing the use of domestic inputs and increasing the use of more productive imported inputs. To see that, in the closed economy, the total expenditure share on sectors with productivity growth rates below $\theta^{*} g_{A}$ is $F\left(\theta^{*}\right)$, while this drops to $F\left(\theta^{*}\right) /\left(1+m\left[1-F\left(\theta^{*}\right)\right]\right)$ in the open economy. Note that this feature would not arise without sectorial heterogeneity. If all sectors have the same productivity growth rates, economic growth in both closed and open economies is the same. In this sense, this paper complements the recent literature on trade-based firm heterogeneity on the level of productivity. The contribution of this paper is that we are able to show the growth effect rather than the level effect as shown in the existing literature.

\section{The Interaction between Trade and Growth}

Now we are ready to answer the central question of this paper: Can trade increase economic growth? As the following proposition suggests, the answer is yes. To focus on non-trivial cases, we let $\phi$ be in the interval $\left(\phi_{\min }, \phi_{\max }\right)$ in the following discussion.

Proposition 3. The economic growth rate in the open economy is higher than that in closed economy.

Proof. The growth rate in the closed economy, $g_{Y}=\bar{\theta} g_{A}$. According to equation (38), the growth rate in the open economy can be written as $\tilde{g}_{Y}=\frac{1}{\Omega}\left[\int_{0}^{1} \theta f(\theta) d \theta+m \int_{\theta^{*}}^{1} \theta f(\theta) d \theta\right] g_{A}$. Define $\hat{\theta}=\frac{1}{1-F\left(\theta^{*}\right)} \int_{\theta^{*}}^{1} \theta f(\theta) d \theta$ as the mean of $\theta$ conditioned on $\theta>\theta^{*}$. The growth rate in the open economy can be written as $\tilde{g}_{Y}=(\lambda \hat{\theta}+(1-\lambda) \bar{\theta}) g_{A}$ with $\lambda=\frac{m\left[1-F\left(\theta^{*}\right)\right]}{1+m\left[1-F\left(\theta^{*}\right)\right]}$. As $\hat{\theta}>\bar{\theta}$, we have $\tilde{g}_{Y}>\bar{\theta} g_{A}=g_{Y}$.

REMARK: The increase in the growth rate is as follows:

$$
\tilde{g}_{Y}-g_{Y}=\lambda(\hat{\theta}-\bar{\theta}) g_{A},
$$

which contains some interesting features. To understand the impact of trade on economic growth, we follow Melitz (2003) to investigate two mechanisms that can lead to an increase in the exposure to trade, namely, an increase in the number of trading partners and a decrease 
in the fixed cost of exporting. Interestingly, the results obtained below under these two mechanisms are different.

\subsection{An Increase in the Number of Trading Partners}

The effects of an increase in $m$ are depicted in Figure 3.

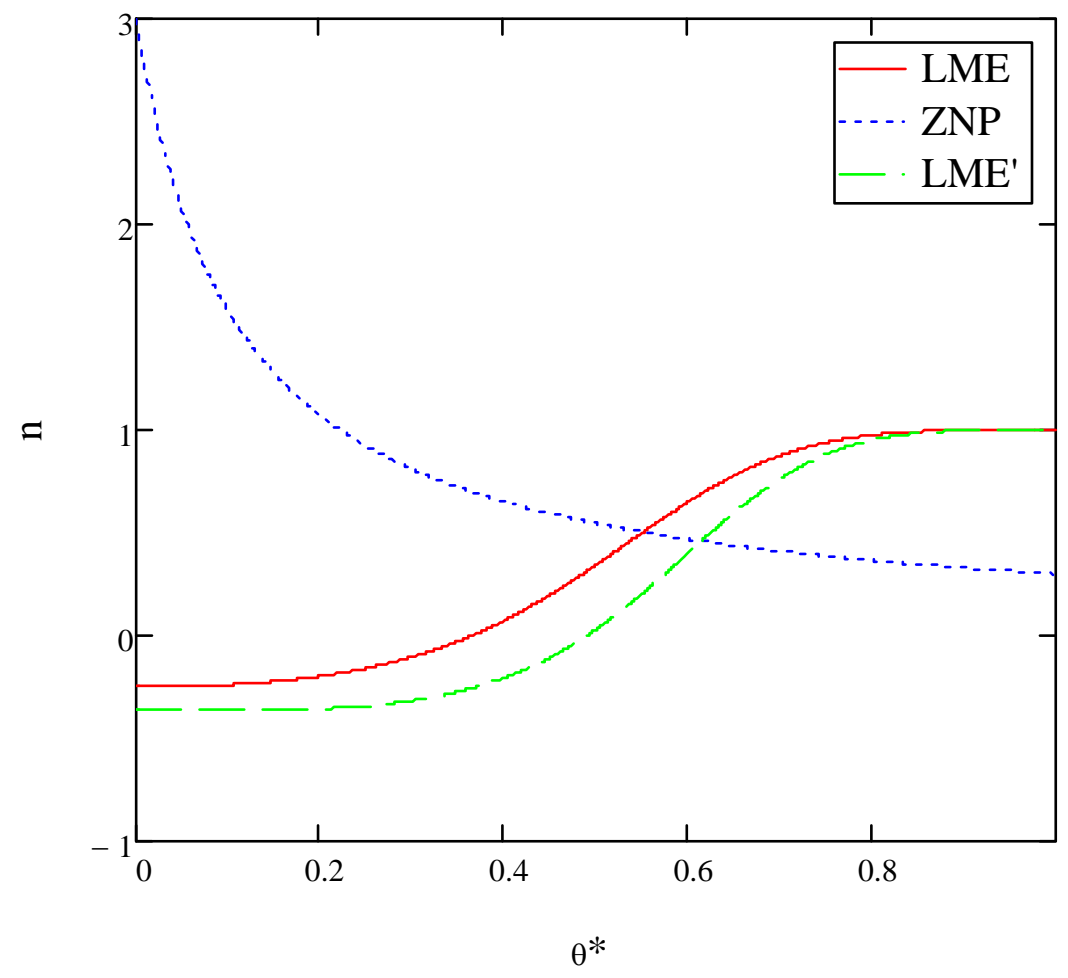

Figure 3. An Increase in the Number of Trading Partners

The ZNP curve is unchanged, but an increase in trading partners shifts the LME curve to the right, to LME'. As a result, a smaller fraction of sectors trade in the equilibrium. However, the overall effect on the growth rate is not that obvious. As $\theta^{*}$ increases, the

conditional mean, $\hat{\theta}$, increases. This effect alone would increase the economic growth rate (see equation 39 ). But as $m$ increases, $\left[1-F\left(\theta^{*}\right)\right]$ decreases. Thus, the variety of the total available imported goods, $m\left[1-F\left(\theta^{*}\right)\right]$, could decrease. If this is the case, then this effect would decrease the growth rate (again, see equation 39). Luckily, we are able to show that this case never arises.

Note that the labor market equilibrium can also be written as $n\left[1+\frac{m\left[1-F\left(\theta^{*}\right)\right](1-\hat{\theta})}{1-\theta}\right]+$ $\phi m\left[1-F\left(\theta^{*}\right)\right]=N$. Using this relationship, we have $m\left[1-F\left(\theta^{*}\right)\right]=(N-n) /\left(\phi+n \frac{1-\hat{\theta}}{1-\theta}\right)$. As Figure 2 shows, an increase in $m$ leads to a decrease in $n$ and an increase in $\theta^{*}$ (hence an 
increase in $\hat{\theta}$ according to the its definition). Therefore, $m\left[1-F\left(\theta^{*}\right)\right]$ increases unambiguously in $m$. We thus establish the following proposition.

Proposition 4. An increase in the number of trading partners enhances economic growth.

Intuitively, equation (39) states that economic growth in the open economy depends on $\hat{\theta}$ and $\lambda$. Thus, there are two effects working in the same direction: the resource reallocation effect and the total product-variety effect. More trading partners intensify the competition and resources will be reallocated toward the sectors with higher productivity growth (see Figure 4), inducing higher overall growth. The total product-variety effect is less straightforward than we might otherwise think. As the number of trading partners increases, each country exports a narrower set of goods as we discussed above, but the total variety of exports, $m\left[1-F\left(\theta^{*}\right)\right]$, expands, leading to higher overall growth.

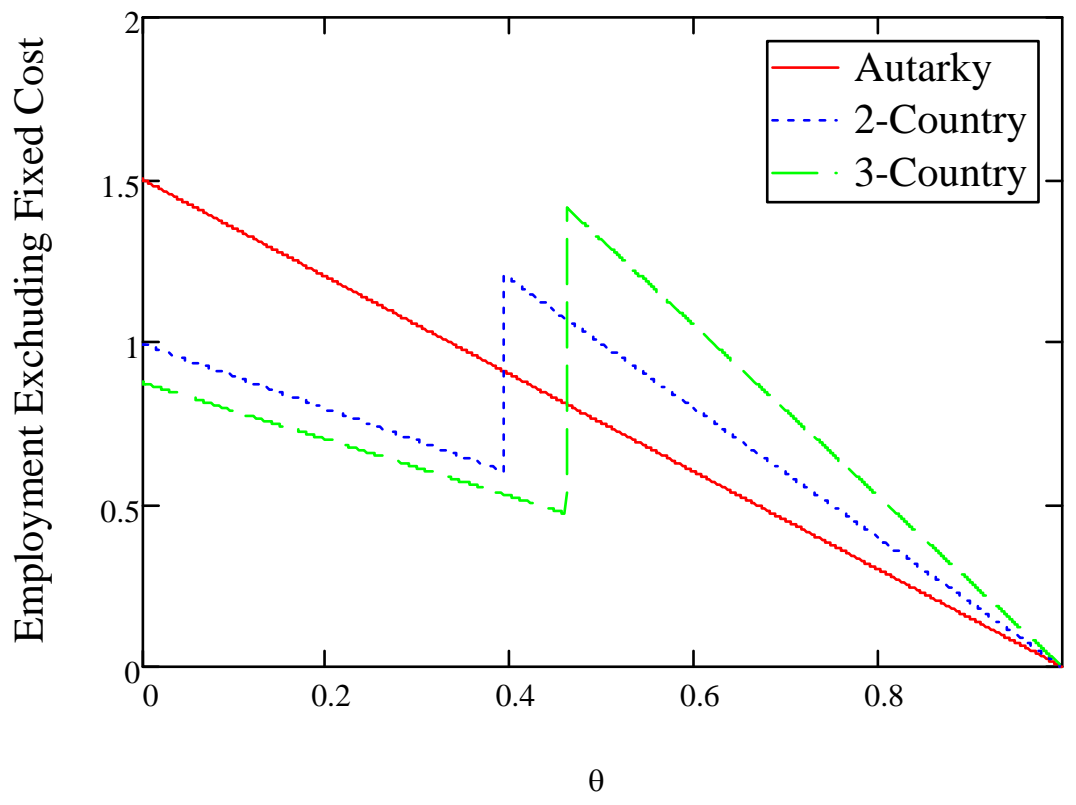

Figure 4. Resource Reallocation as $m$ Increases

\subsection{The Effect of a Lower Fixed Cost}

The effect of a lower trade cost is not that obvious. As Figure 2 shows, in one extreme case (the right panel), if the fixed cost decreases below $\phi_{\min }$, all sectors trade. Hence, we have $\hat{\theta}=\bar{\theta}$ and thus $\tilde{g}_{Y}-g_{Y}=0$ (see equation 39). In the other extreme case (Figure 2 , the left panel), if the fixed cost increases above $\phi_{\max }$, none of the sectors trade, hence $m\left[1-F\left(\theta^{*}\right)\right]=0$, again leading to $\tilde{g}_{Y}-g_{Y}=0$ (see equation 39 ). This implies the growth rate is not a monotonic function of the fixed cost. 
As in the previous example, the increase in the transaction cost has the same two effects: the resource reallocation effect and the total product-variety effect; but, in this case, they work in opposite directions, leading to a hump-shaped impact on growth (see Figure 5). Whereas the resource reallocation effect (see Figure 6) continues to induce higher growth because the average growth rates of the exporters are pushed higher by the higher fixed cost, the total product-variety available to each country shrinks.

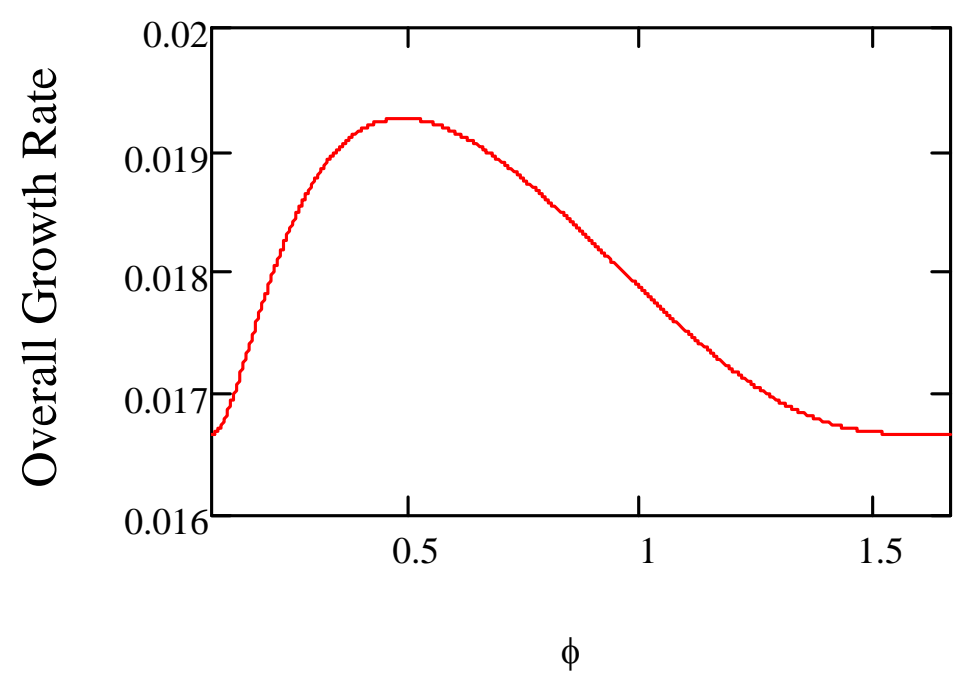

Figure 5. Overall Growth Rate as a Function of $\phi$

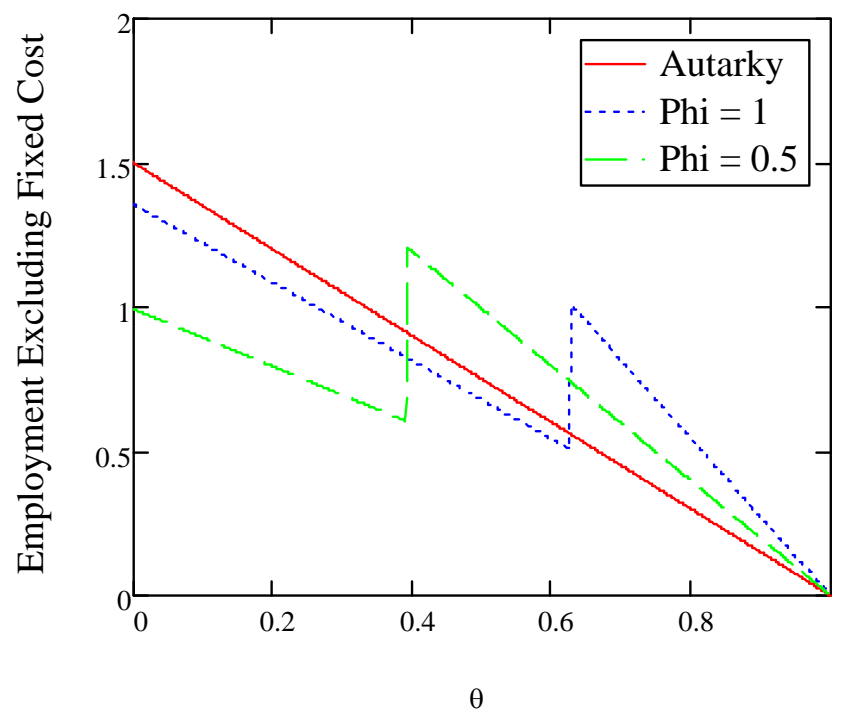

Figure 6. Resource Reallocation as $\phi$ Increases 


\section{Concluding Comments}

As far as we know, this is the first attempt to build a dynamic growth model that includes heterogeneity in productivity growth across sectors. We show that although the growth rate in each sector is exogenous, the overall growth rate is endogenous, depending on labor intensity in a closed economy and depending further on trade parameters in an open economy. We discussed how parameters that affect trade patterns would affect the overall growth rate of an economy. The model could also be used to discuss fiscal, industrial, and tariff policies, which we leave for future study.

Another area for future study is to introduce capital into the model. In this richer setting, one would be able to discuss investment and savings decisions and intertemporal trade-offs.

Finally, the most difficult exercise would be to allow for non-symmetry across countries. Such a framework would be useful to discuss trade and FDI patterns as well as convergence and might generate insights on different industrial policies on the parts of developed and developing economies. 


\section{Appendix: Proof of Proposition 1}

LEMma 1. The necessary condition for $I=\emptyset$ is $\phi>\phi_{\max }$ and the necessary condition for $I=\Gamma$ is $\phi \leq \phi_{\min }$.

Proof. $I=\emptyset$ means that for all $\theta$, the net profit for exporting $\left[1-\frac{\sigma-1}{\sigma}(1-\theta)\right] \frac{Y}{\Omega}-\phi w$ is negative (with $\Omega=1$ ). In particular, for $\theta=1$, we must have $Y-\phi w<0$. Also, for all $i$, we must have

$$
\frac{\sigma-1}{\sigma}\left(1-\theta_{i}\right) P(i) Y(i)=w N(i)
$$

which comes from the profit maximization condition, (29), for the intermediate goods producers. Now integrating equation (A1) across all sectors yields $\frac{\sigma-1}{\sigma}(1-\bar{\theta}) Y=w N$. We thus have $\frac{\sigma w N}{(\sigma-1)(1-\bar{\theta})}=Y<\phi w$, which is identical to $\phi>\phi_{\max }$.

$I=\Gamma$ means that for all $\theta$, the net profit for exporting $\left[1-\frac{\sigma-1}{\sigma}(1-\theta)\right] \frac{Y}{\Omega}-\phi w$ is nonnegative (with $\Omega=2$ ). Thus, in particular, for $\theta=0$, we must have $\frac{1}{2 \sigma} Y-\phi w \geq 0$. Let $2 n_{0}+\phi$ be the total employment in the sector with $\theta=0$ (fixed cost included), the total employment in sector $\theta$ is $2 n_{0}(1-\theta)+\phi$. The labor market equilibrium condition is given by $2 n_{0}(1-\bar{\theta})+\phi=N$. For sector $\theta=0$, the profit maximizing condition (27) implies $2 w n_{0}=\frac{\sigma-1}{\sigma} Y$. Hence,

$$
\begin{aligned}
\phi & =N-2 n_{0}(1-\bar{\theta}) \\
& =N-\frac{\sigma-1}{\sigma}(1-\bar{\theta}) \frac{Y}{w} \\
& \leq N-\frac{\sigma-1}{\sigma}(1-\bar{\theta}) 2 \sigma \phi,
\end{aligned}
$$

which yields

$$
\phi \leq \frac{N}{1+2(\sigma-1)(1-\bar{\theta})}=\phi_{\min }
$$

LEMma 2. If $\phi \in\left(\phi_{\min }, \phi_{\max }\right]$, then $I=\left\{i \mid 1 \geq \theta_{i} \geq \theta^{*}>0\right\}$ with $\theta^{*}$ as the solution to (34) and (35).

Proof. From Lemma 1, I must be a non-trivial subset of $\Gamma$. Given that the net profit from exporting is an increasing function of $\theta$, the set $I$ has to take the form $I=\left\{i \mid 1>\theta_{i} \geq \theta^{*}>0\right\}$. To determine $\theta^{*}$, we make use of labor market equilibrium condition and the zero-net profit condition at $\theta^{*}$. Note that the total labor employment, $N(\theta)$, in sector $\theta$, is given as follows:

$$
N(\theta)=\left\{\begin{array}{cc}
\frac{1-\theta}{1-\theta^{*}} 2 n^{*}+\phi & \text { for } \theta \geq \theta^{*} \\
\frac{1-\theta}{1-\theta^{*}} n^{*} & \text { for } \theta<\theta^{*}
\end{array},\right.
$$

where $2 n^{*}+\phi$ is the total employment in sector $\theta^{*}$. Hence, the labor market equilibrium condition can be written as:

$$
n^{*}\left[\frac{1-\bar{\theta}}{1-\theta^{*}}+\frac{1}{1-\theta^{*}} \int_{\theta^{*}}^{1}(1-\theta) f(\theta) d \theta\right]+\phi\left[1-F\left(\theta^{*}\right)\right]=N .
$$


To compute the net profit, note that the profit maximizing condition (27) implies (when $\left.\theta=\theta^{*}\right)$

$$
w 2 n^{*}=\frac{\sigma-1}{\sigma}\left(1-\theta^{*}\right) \frac{2 Y}{\Omega}
$$

The zero-net profit condition at $\theta^{*}$ requires

$$
\left[1-\frac{\sigma-1}{\sigma}\left(1-\theta^{*}\right)\right] \frac{Y}{\Omega}-\phi w=0,
$$

which, when $Y / \Omega$ is substituted out using equation (A2), reduces to:

$$
\left[\frac{1}{\frac{\sigma-1}{\sigma}\left(1-\theta^{*}\right)}-1\right] n^{*}=\phi
$$

REMARK. In the proof of Lemma 2 , it is clear that the statement $I=\left\{i \mid 1>\theta_{i} \geq \theta^{*}>0\right\}$ with $\theta^{*}$ as the solution to (34) and (35) is equivalent to " $I$ is a non-trivial subset of $\Gamma$."

Lemma 3. If $I=\left\{i \mid 1>\theta_{i} \geq \theta^{*}>0\right\}$ with $\theta^{*}$ as the solution to (34) and (35), then $\phi \in\left(\phi_{\min }, \phi_{\max }\right]$.

Proof. If $I=\left\{i \mid 1 \geq \theta_{i} \geq \theta^{*}>0\right\}$ with $\theta^{*}$ as the solution to (34) and (35), the two equations can be combined to yield:

$$
\phi=\frac{N}{\frac{1}{\left.\frac{\sigma}{\sigma-1}-\left(1-\theta^{*}\right)\right]}\left[1-\bar{\theta}+\int_{\theta^{*}}^{1}(1-\theta) f(\theta) d \theta\right]+\left[1-F\left(\theta^{*}\right)\right]},
$$

which is increasing in $\theta^{*}$. Therefore, noting that $\theta^{*}$ is in $(0,1]$, we must have:

$$
\frac{N}{(\sigma-1)[2-2 \bar{\theta}]+1}<\phi \leq \frac{\sigma N}{(\sigma-1)[1-\bar{\theta}]} .
$$

Summary. It remains to argue that if $\phi>\phi_{\max }, I=\emptyset$ and if $\phi \leq \phi_{\min }, I=\Gamma$. Lemma 3 and the Remark on Lemma 2 imply that if $\phi>\phi_{\max }$, then $I$ is a trivial subset of $\Gamma$, namely $I=\emptyset$ or $I=\Gamma$. But we know from Lemma 2 that $I=\Gamma$ requires $\phi \leq \phi_{\min }$, which is impossible. Hence, $I=\emptyset$. Similarly, we can argue that $\phi \leq \phi_{\min }$ implies that $I=\Gamma$. 


\section{References}

[1] Acemoglu, Daron, Pol Antras and Elhanan Helpman (2007), "Contracts and Technology Adoption", American Economic Review, Vol. 97(3), pp. 916-943.

[2] Aghion, Philippe and Peter Howitt (1992) "A Model of Growth Through Creative Destruction", Econometrica, Vol. 60(2), pp. 323-351.

[3] Alcalá, Francisco and Antonio Ciccone (2004), "Trade and Productivity", Quarterly Journal of Economics, Vol. 119(2), pp. 612-645.

[4] Aw, Bee Yan, Sukkyun Chung and Mark Roberts (2000), "Productivity and Turnover in the Export Market: Micro Evidence from Taiwan and South Korea", World Bank Economic Review, Vol. 14(1), pp. 65-90.

[5] Bernard, Andrew and Charles I. Jones, (1996), "Productivity Across Industries and Countries: Time Series Theory and Evidence," Review of Economics and Statistics, Vol. 78 , No. 1, pp. 135-146.

[6] Bernard, Andrew and Bradford Jensen (1995), "Exporters, Jobs, and Wages in U.S. Manufacturing: 1976-1987", Brookings Papers on Economic Activity: Microeconomics, pp. 67-119.

[7] Bernard, Andrew and Bradford Jensen (1999), "Exceptional Exporter Performance: Cause, Effect, or Both?", Journal of International Economics, Vol. 47(1), pp. 1-25.

[8] Bernard, Andrew, Jonathan Eaton, Bradford Jensen and Samuel Kortum ( 2003), "Plants and Productivity in International Trade", American Economic Review, Vol. 93(4), pp.1268-1290.

[9] Bernard, Andrew, Stephen Redding and Peter Schott (2007), "Comparative Advantage and Heterogeneous Firms", Review of Economic Studies, Vol. 74(1), pp.31-66.

[10] Eaton, Jonathan, and Samuel Kortum (2002), "Technology, Geography, and Trade", Econometrica. Vol.70, pp. 1741-1779.

[11] Frankel, Jeffrey and David Romer (1999), "Does Trade Cause Growth?", American Economic Review, Vol. 89(3), pp. 379-399.

[12] Ghironi, Fabio and Marc Melitz (2005), "International Trade and Macroeconomic Dynamics with Heterogeneous Firms", Quarterly Journal of Economics, Vol. 120(3), pp. 865-915.

[13] Grossman, Gene and Elhanan Helpman (1991), Innovation and Growth in the Global Economy, Cambridge MA, MIT Press. 
[14] Helpman, Elhanan, Marc Melitz and Stephen Yeaple (2004), "Export Versus FDI with Heterogeneous Firms." American Economic Review Vol. 94(1), pp. 300-316.

[15] Jones, Charles (1995), "R \& D-Based Models of Economic Growth" ,Journal of Political Economy, Vol. 103(4), pp. 759-784.

[16] Jorgenson, Dale W. and Frank M. Gollop (1992), "Productivity Growth in U.S. Agriculture: A Postwar Perspective," American Journal of Agricultural Economics, Vol. 74, No. 3, pp. $745-750$

[17] Lucas, Robert Jr. (2007), "Trade and the Diffusion of the Industrial Revolution", NBER Working Paper, No. 13286.

[18] Lucas, Robert Jr. (1988), "On the Mechanics of Economic Development", Journal of Monetary Economics, Vol. 22(1), pp. 3-42.

[19] Melitz, Marc (2003), "The Impact of Trade on Intra-Industry Reallocations and Aggregate Industry Productivity", Econometrica, Vol. 71, pp. 1695-1725.

[20] Melitz, Marc (2007), "International Trade and Heterogeneous Firms", Forthcoming at New Palgrave Dictionary of Economics, Second Edition.

[21] Melitz, Marc and Giancarlo Ottaviano (2008), "Market Size, Trade, and Productivity", Review of Economic Studies, Vol. 75(1), pp. 295-316.

[22] Romer, Paul (1986), "Increasing Returns and Long-Run Growth", Journal of Political Economy, October Vol. 94, pp.1002-38.

[23] Romer, Paul (1990), "Endogenous Technological Change", Journal of Political Economy, Vol. 98(5), pp.71-102.

[24] Sachs, Jeffrey D. and Andrew, Warner. 1995. "Economic Reform and the Process of Global Integration," Brookings Papers on Economic Activity, pp. 1-118.

[25] Sala-I-Martin, Xavier X (1997), "I Just Ran Two Million Regressions," American Economic Review, Vol. 87, No. 2, pp. 178-183.

[26] Solow, Robert (1956), "A Contribution to the Theory of Economic Growth", Quarterly Journal of Economics, Vol. 70(1), pp. 65-94. 